ORIGINAL ARTICLE

\title{
The threat to scientific integrity in environmental and occupational medicine
}

\author{
S Tong, J Olsen
}

Occup Environ Med 2005;62:843-846. doi: 10.1136/oem.2005.021410

See end of article for authors' affiliations

.....................

Correspondence to: Associate Professor S Tong, School of Public Health, Queensland University of Technology, Kelvin Grove, Queensland 4059, Australia; s.tong@ qut.edu.au

Accepted 27 May 2005
Over the last century, environmental and occupational medicine has played a significant role in the protection and improvement of public health. However, scientific integrity in this field has been increasingly threatened by pressure from some industries and governments. For example, it has been reported that the tobacco industry manipulated eminent scientists to legitimise their industrial positions, irresponsibly distorted risk and deliberately subverted scientific processes, and influenced many organisations in receipt of tobacco funding. Many environmental whistleblowers were sued and encountered numerous personal attacks. In some countries, scientific findings have been suppressed and distorted, and scientific advisory committees manipulated for political purposes by government agencies. How to respond to these threats is an important challenge for environmental and occupational medicine professionals and their societies. The authors recommend that professional organisations adopt a code of ethics that requires openness from public health professionals; that they not undertake research or use data where they do not have freedom to publish their results if these data have public health implications; that they disclose all possible conflicts; that the veracity of their research results should not be compromised; and that their research independence be protected through professional and legal support. The authors furthermore recommend that research funding for public health not be directly from the industry to the researcher. An independent, intermediate funding scheme should be established to ensure that there is no pressure to analyse data and publish results in bad faith. Such a funding system should also provide equal competition for funds and selection of the best proposals according to standard scientific criteria.
O ver the last century, environmental and occupational medicine has played a significant role in the control and prevention of environmental and occupational diseases such as water, food, and vector borne diseases, occupational health problems caused by exposure to physical (for example, traumatic injury, noise, radiation, heat, and cold), chemical (for example, silica/silicates, heavy metals, and pesticides), and biological hazards (for example, HIV, tuberculosis, and hepatitis). ${ }^{1}$ However, like other scientific fields, the role of private sector in funding environmental and occupational health research is increasing and the well developed guidelines for government sponsored research usually do not apply to the academic industry arena. ${ }^{2}$ For example, in the USA, the proportion of health research and development funded by federal sources declined by almost half to approximately $37 \%$ between 1965 and 1995, while industry's funding increased more than twofold, to $52 \%$ of the total US $\$ 35.8$ billion expended. ${ }^{3}$ There are inherent problems with industry sponsored research in relation to intellectual property and ethical issues because industry funders and academic researchers work in different systems with differing goals and means. Thus, scientific integrity and concern for the health of the people in environmental and occupational medicine has been increasingly threatened by pressures from industries and sometimes governments as well. Such a threat may not only impair opportunities for disease prevention but also reduce credibility in public health science.

The increasing role of industry sponsored research, despite its many benefits, raises concerns. At the extreme are instances in which an industry sponsors research with the direct goal of countering existing scientific evidence. ${ }^{4}$ Unfortunately, the history of environmental and occupational medicine has been littered with such cases over the last century. Dr Irving Selikoff, for example, was on the leading edge of a challenge to the asbestos industry and was one of this century's foremost advocates of worker health. ${ }^{5}$ His work has been attacked ${ }^{6}$ even though the asbestos cancer epidemic may take millions of lives before asbestos is banned worldwide and exposures are brought to an end. ${ }^{7}$ It is reported that studies funded by pharmaceutical companies were approximately one eighth as likely to reach unfavourable qualitative conclusions and 2.4-fold as likely to reach favourable quantitative conclusions than non-profit sponsored studies. ${ }^{8}$ Financial conflict of interest is a fundamental and pressing issue for environmental and occupational health research because it may adversely affect scientific integrity through the delaying or withholding of research results and by directly or indirectly influencing the content of results. ${ }^{4}$ Therefore, it is important to identify key issues that undermine integrity in the conduct of environmental and occupational health research such as who does it, who funds it, and how does science lead to policy?

We use the following examples to further illustrate these important issues.

\section{THREAT FROM INDUSTRIES \\ Tobacco and health}

Tobacco causes over a third of all cancer deaths. Half of all smokers will die from a tobacco related disease. Half of these will die in middle age, with a loss of 15-20 years of his or her life. ${ }^{9}$ The rapid rise in smoking in many developing countries will have devastating consequences; by 2030 the developing world is expected to have 7 million deaths annually from tobacco use. ${ }^{10}$ The tobacco industry has been aware of the serious health impact of its products for decades but has sought to conceal the evidence from its customers and has consistently, and cynically, refuted the findings of the scientific community. It has irresponsibly and aggressively

Abbreviations: $\mathrm{ICOH}$, International Commission on Occupational Health; ILZRO, International Lead Zinc Research Organisation 
promoted its products to the young, women, and the poor, particularly in developing countries. ${ }^{11}$ The health consequences from this have been enormous.

Although the toll of tobacco related disease and death continues to grow worldwide, the tobacco industry continues to use a vast array of strategies to promote its products and increase profits. They have been reported to behave inappropriately in numerous ways, including:

1. Attempting to manipulate eminent scientists. Dr Ernst Wynder is the founder of the American Health Foundation, and the emergence of smoking as a priority issue on the American public health agenda can be largely attributed to Wynder's efforts. The Philip Morris tobacco company pursued and manipulated Wynder between 1955 and 1995 to legitimise their company positions. ${ }^{12}$ Philip Morris viewed Wynder as a famous scientist whose interest to pursue less harmful cigarettes could lend legitimacy to its desire to position itself as a responsible company intent on addressing consumer concerns. Philip Morris therefore provided Wynder with equipment loans and grants for more than 30 years, and used its public relations agency to sanitise press releases to remove material unacceptable to the company. During 197395. Wynder's American Health Foundation received over $\$ 5.7$ million funding support from Philip Morris. ${ }^{12}{ }^{13}$ Even in the 1950s Wynder began a long time working relationship with Lorillard scientists that included the evaluation of experimental filters and chemically treated tobacco. ${ }^{13-15}$ Wynder was an incessant voice for public health action to reduce the morbidity and mortality associated with tobacco use and realised the insidious effect of tobacco industry research support but consistently failed to acknowledge his own association with the industry. ${ }^{12}{ }^{13}$

2. Influencing governments, companies, and universities that are in receipt of tobacco money.

Many governments garner tax revenues generated from the sale of tobacco. The organisers of major sporting and cultural events in developing countries often rely on tobacco funds and are now fighting along with the tobacco industry against restrictions on sponsorship (it is banned, fortunately, in many developed countries). In addition, universities and healthcare institutions may also depend on tobacco industry funding and connections. Such funding poses the potential of conflict of interest, because these institutions are implicitly entrusted with researching and publicising the harmful effects of tobacco and the role of the tobacco industry. ${ }^{16}$ For example, over half of American medical schools acknowledged research funding from the tobacco industry and its subsidiaries in the early 1990s. ${ }^{17}$ In the United Kingdom, only one medical school (Glasgow) did not receive tobacco industry funding between 1988 and $1994 .{ }^{18}$ Much of this funding has been directly from people with financial interest in selling tobacco products to scientists.

3. Distorting risk and subverting scientific processes. There are many groups and consultants who were funded by the tobacco industry-both directly and indirectly-and who provided the industry with ample materials in the form of testimony, reports, and other publications to fight tobacco policy and regulations. Recently, Ong and Glantz ${ }^{19}$ elegantly reviewed tobacco industry efforts to subvert the International Agency for Research on Cancer's second hand smoke study. Clearly, the tobacco industry has been undermining the basis of trust in science. ${ }^{20}$ Recently, there is new evidence indicating that the tobacco industry may have been unduly influencial on the editorial boards and contents of some journals. ${ }^{21}$

Worldwide, smoking caused about 3 million deaths in 1990, out of a total of 30 million adult deaths from all causes, and it will cause about 10 million in 2030, out of a total of about 60 million. ${ }^{22}$ Yet only a few doctors and health professionals campaign for action on tobacco; most bureaucrats remain cautious; health generally loses out when it comes into conflict with more important government departments; politicians with the determination to act on tobacco are rare and are soon moved; and the tobacco manufacturers and their agents are if anything tougher and nastier than ever. Some responsibility for these deaths rests not only with the tobacco industry, but also with its many active and passive allies in government and with hired experts who helped distort and manipulate scientific findings. ${ }^{23}$

Many universities and research institutions in developed countries no longer accept money from the tobacco industry. The history does justify concern for a continuing influence on policy making based upon the tobacco industry's economic interests. We suggest that money from the tobacco industry still be used to pay for research but that this funding should always be indirect. Money from the industry should be given to an independent funding organisation that selects the best qualified applicants. There should be no direct links between the industry and the researcher.

\section{Lead and cognition}

In 1979, Dr Herbert Needleman published his landmark paper on the effect of exposure to environmental lead on children's cognitive development in the New England Journal of Medicine. This article pointed to a health effect that was serious, widespread, and directly linked to lead in paint and gasoline. The industry's reaction was swift and massive. The International Lead Zinc Research Organisation (ILZRO), an industry group, hired dozens of scientists including the psychologist Claire Ernhart of Case Western Reserve University in an effort to discredit Needleman's work. In 1982, the ILZRO charged that Needleman had committed misconduct in carrying out this study for not taking account of the possible impact of social class and measurement errors in assessing intelligence and behaviour. ${ }^{24}$ The United States Environmental Protection Agency (EPA), in response to these charges, formed a committee to review Needleman's study. The committee audited all of Needleman's files in this study and found only minor statistical errors in some of the work. However, a decade later, Ernhart et $a l^{25}$ again accused Needleman of scientific misconduct, echoing the claims made earlier by ILZRO. At that time, it was unknown that their charges were actually supported by the lead industries. Dr Needleman was again cleared of all misconduct charges but spent more than 15 years and thousands of dollars. In a letter to the Editor published in Pediatrics in 1993, Needleman wrote: "The lead industry was already accustomed to fighting battles over science and economics by the 1920's. To keep lead in paint, the industry relied on the quasi-scientific suggestion apparently introduced in the mid-20's by a Harvard physician whose research was supported by the industry. He claimed that a child who ate lead paint chips was somehow inherently 'defective'... Seventy years later, the industry is still using these tactics, By zeroing in on one or two scientists and mounting personal attacks on their integrity and credibility, the industry has generated enough fog to blur the truth...". ${ }^{26}$ Dr Needleman was successful in his response to the industry not only because the issues in contention were, if anything, matters of disagreement in methods of data analysis and not fraud or misconduct, but also because numerous scientists supported him..$^{28} \mathrm{Dr}$ Needleman has survived these personal attacks and his findings have been corroborated by many other studies. However, there has been a serious impact of the pressure from some industries on many environmental whistleblowers. ${ }^{29}$

\section{Conflicts of interest}

It is difficult to obtain the necessary scientific integrity when a company with substantial financial interests directly pays 
the scientist to study the benefits and side effects of its products. As a first step to reach more objective conclusions, the scientists should disclose their financial sources for the research they report. Although this is a rather obvious requirement, it has not been well practiced in the past. For instance, in a recent survey of 48 journals in science and clinical medicine, only 20 journals $(43 \%)$ reported that they had policies requiring disclosure of conflict of interest. ${ }^{30}$ Scientists have a professional responsibility to ensure that the integrity of researchers, subjects, and the research process is well protected if private funding is involved. Additionally, good practice guidelines for privately funded environmental and occupational health research are necessary. ${ }^{2}$

Recognising that direct funding always produces some dependency between the sponsor and the recipient, there is a need to separate scientists from industry funders with some kind of intermediate agency. An intermediate agency, such as a medical research council, should be the sole funding source for public health research, regardless of whether the money comes from private or public sources. Not only would that provide much looser links (or at best, no links) between the sponsor and the recipient, but it could also allow healthy competition on quality criteria for funds. Such a system is essential when research involves public health issues that may interfere with the financial interests of a company.

It is sometimes difficult to protect scientists from political pressure. Epidemics like HIV, BSE, SARS, and bird influenza have had enormous impact on many aspects of politics and economics. Substantial pressure from industries and governments could be put on scientists to defer from informing the public of perceived or real health threats. Legal protection and collegial support from professional societies and other intermediate agencies are needed.

\section{THREAT FROM GOVERNMENTS}

Research integrity depends largely on researcher independence. However, there is substantial divergence between the scientific community's standards for ensuring research integrity and the ad hoc protections for researcher independence tolerated by national regulatory agencies. ${ }^{31}$ Conflict of interest concerns have grown at universities and research institutions as the pressure for funding and the involvement of these institutions in commercial enterprises and connections increase. ${ }^{32} 33$

Application of science plays an increasing role in government decisions, clinical decision making, and public policies. Evidence based principles underpin systematic reviews like those performed by both the Cochrane and Campbell centres, and although the term "evidence" promises more than we can deliver, it is a proper target to aim at. Scientific input, although it is only one of many factors considered in the decision making process, should always be valued and weighed from an objective and impartial perspective to avoid adverse consequences. ${ }^{34}$ However, this principle has been disregarded by some governments and international organisations. ${ }^{35}{ }^{36}$ For example, the International Commission on Occupational Health ( $\mathrm{ICOH}$ ) has played a significant role in some aspects of research in occupational health but has had problems with its association with the industry. Many ICOH members are employees of corporations or consultants to industry, serving multinational corporate interests to influence public health policy in the guise of a professional scientific organisation. ICOH members' conflicts of interest with public health dominate the organisation and damage the standing of the ICOH.

Recently, the number of scientists calling for an end to these practices and restoration of scientific integrity in the US national policymaking now totals more than 5000, including 48 Nobel laureates, 62 National Medal of Science recipients, and 127 members of the National Academy of Sciences. ${ }^{37}$ They indicated: "When scientific knowledge has been found to be in conflict with its political goals, the administration has often manipulated the process through which science enters into its decisions. This has been done by placing people who are professionally unqualified or who have clear conflicts of interest in official posts and on scientific advisory committees; by disbanding existing advisory committees; by censoring and suppressing reports by the government's own scientists; and by simply not seeking independent scientific advice ... Furthermore, in advocating policies that are not scientifically sound, the administration has sometimes misrepresented scientific knowledge and misled the public about the implications of its policies". ${ }^{35}$

Recently, the new cases released by the Union of Concerned Scientists detail incidents of suppression and distortion of scientific knowledge on issues ranging from mountaintop removal strip mining to endangered species. Included in these additional cases are numerous new accounts of political interference with independent scientific advisory panels. ${ }^{38}$

The Union of Concerned Scientists proposed measures to rectify the situation and restore the scientific integrity in policy making, including: ${ }^{38}$

- "whistleblower" protection of scientists;

- restoring independent scientific advice to Congress;

- greater oversight powers for the Office of Science and Technology Policy;

- stricter enforcement of the Federal Advisory Committee Act with increased transparency for selection and activities of advisory committees; and

- full access to government scientific analysis that is not legitimately classified for national security reasons.

As Robbins recently pointed out, "most Americans would be distressed to learn that US policies on stem cell research, global warming, and condoms-all driven at present by politics rather than science-are already diminishing the effectiveness of humanitarian nongovernmental and international organisations globally." ${ }^{\prime 39}$ It may also be worth noting that the USA is not the only place where such problems arise. For example, China is developing rapidly as a major economic force in Asia and in the world at large, but is not yet fulfilling its scientific potential, despite its remarkable economic development over the last two decades and major expenditure on science. The major reasons for this include politics driven/non-science based decision making, inadequate funding review processes, and the lack of a dynamic research environment. ${ }^{40}{ }^{41}$ This results not only in a low scientific profile on the world stage, but also in lost opportunities to make the most of what the rest of the world can offer, both scientifically and technologically. This also leads to missed opportunities for China to improve both its economy and the quality of life for its citizens. ${ }^{42}$

\section{CONCLUSION}

Although environmental and occupational medicine plays an important role in the protection and improvement of population health through the control and prevention of environmental and occupational disease, scientific integrity in this field has been increasingly threatened by pressures from some industries and governments. How to respond to these threats is an important challenge for environmental and occupational medicine professionals. We recommend that professional organisations such as the ICOH, International Society for Environmental Epidemiology, and International Epidemiological Association adopt a code of ethics that requires openness from public health professionals: that they not 


\section{Main messages}

- Scientific integrity in environmental and occupational medicine has been increasingly threatened by pressures from some industries and governments.

- This threat may not only impair opportunities for disease prevention but also reduce credibility in public health science and is an important challenge for environmental and occupational medicine professionals and their societies.

\section{Policy implications}

- Professional organisations need to adopt a code of ethics that requires openness from public health professionals.

- Research funding for public health should not come directly from the industry to the researcher; an independent, intermediate funding scheme should be established.

undertake research or use data where they do not have freedom to publish their results without prior approval, at least not for research problems that address issues which concern public health; that they disclose all possible conflicts; that veracity of their research results should not be compromised; and that their research independence be protected through professional and legal support. It is reassuring to see that some of these measures have been incorporated in the recent proposal prepared for the International Epidemiology Association European Federation's Good Epidemiological Practice document on proper conduct in epidemiological research. This document is an introduction to the principles of how best to follow accepted ethical codes (for example, autonomy, beneficence, non-maleficence, and justice) while maintaining good quality research. It is proposed as guidelines for research, collaboration, communication, and peer review in epidemiological research (this document is available from the authors on request). It is anticipated that scientific integrity will be enhanced if these proposed principles are genuinely accepted and stringently practiced by environmental and occupational medicine professionals.

\section{ACKNOWLEDGEMENTS}

The authors thank the editor and two anonymous reviewers for their insightful comments on this manuscript, and Drs Ian Ring, Brian Oldenburg, Anthony Robbins, and David Michaels for the helpful feedback on the early draft.

\section{Authors' affiliations}

S Tong, School of Public Health, Queensland University of Technology, Kelvin Grove, Queensland, Australia

$\mathrm{J}$ Olsen, Department of Epidemiology and Social Medicine, University of Aarhus, Aarhus, Denmark

Competing interests: none

\section{REFERENCES}

1 Rom W. Environmental \& occupational medicine. Philadelphia: LippincottRaven Publishers, 1998.

2 Quinn M, Levenstein C, DeLaurier GF. Good Practice Guidelines for Occupational Health Research Funded by the Private Sector. New Solut 2001;11:303-14.
3 National Centre for Health Statistics. Health, United States, 2000. Hyattsville, MD: National Centre for Health Statistics, 2000:337.

4 Rosenstock L, Lee U. Attacks on science: the risks to evidence-based policy. Am J Public Health 2002;92:14-18.

5 Egilman D, Tweedale G, McCulloch J. PWJ Bartrip's attack on Irving J. Selikoff. Am J Ind Med 2004;46:151-5.

6 Bartrip PWJ. Irving John Selikoff and the strange case of the missing medical degrees. J Hist Med Allied Sci 1993;58:3-33.

7 LaDou J. The asbestos cancer epidemic. Environ Health Perspect 2004; 112:285-90

8 Friedberg $M$, Saffran B, Stinson TJ, et al. Evaluation of conflict of interest in economic analyses of new drugs used in oncology. JAMA, 199920 , 282:1453-7.

9 Peto R, Darby S, Deo H, et al. Smoking, smoking cessation, and lung cancer in the UK since 1950: combination of national statistics with two case-control studies. BMJ 2000;321:323-29.

10 Abdullah AS, Husten CG. Promotion of smoking cessation in developing countries: a framework for urgent public health interventions. Thorax 2004;59:623-30

11 Yach D, Bialous SA. Junking science to promote tobacco. Am J Public Health 2001;91:1745-8.

12 Fields N, Chapman S. Chasing Ernst L Wynder: 40 years of Philip Morris efforts to influence a leading scientist. J Epidemiol Comm Health 2003;57:571-8.

13 Parascandola $M$. Hazardous effects of tobacco industry funding. J Epidemiol Comm Health 2003:57:548-9.

14 Jensen CO. [Letter to Dr E L Wynder, Memorial Hospital]. 7 January 1958. Lorillard. Bates Number: 00066298/6299, Available at hitp:// legacy.library.ucsf.edu/tid/qdm51 e00 (accessed 12 May 2005)

15 Spears AW. [Letter to Dr E L Wynder, Sloan-Kettering Cancer Institute]. 17 March 1962. Lorillard. Bates No. 87657326/7327. Available at http:// legacy.library.ucsf.edu/tid/mnr2le00 (accessed 12 May 2005).

16 Cohen J, Ashley M, Ferrence R, et al. Institutional addiction to tobacco. Tob Control 1999;8:70-4.

17 Blum A. Ethics of tobacco-funded research in US medical schools. Tob Control 1992;1:244-5.

18 Lewison G, Dawson G, Anderson J. Support for UK biomedical research from tobacco industry. Lancet 1997;349:778.

19 Ong E, Glantz S. Tobacco industry efforts subverting International Agency for Research on Cancer's second-hand smoke study. Lancet 2000;355:1253-9.

20 International Agency for Research on Cancer. Available at http:// www.iarc.fr/ENG/Press_Releases/pr158a.html (accessed 15 January 2005).

21 Garne D, Watson M, Chapman S, et al. Environmental tobacco smoke research published in the journal Indoor and Built Environment and associations with the tobacco industry. Lancet 2005;365:804-9.

22 Peto R, Chen ZM, Boreham J. Tobacco-the growing epidemic. Nat Med 1999;5:15-17.

23 Daube M. Political history of smoking and health. Tob Control 2000;9:353-4.

24 Davis $\mathrm{D}$. When smoke ran like water: tales of environmental deception and the battle against pollution. New York: Basic Books, 2002:125-33.

25 Ernhart CB, Scarr S, Geneson DF. On being a whistleblower: the Needleman case. Ethics Behav 1993:3:73-93.

26 Needleman H. A reply to Scarr and Ernhart. Pediatrics 1993:91:519-21.

27 Silbergeld EK. Annotation: protection of the public interest, allegations of scientific misconduct, and the Needleman case. Am J Public Health 1995;85:165-6.

28 Chisholm J, Goldstein G, Cory-Slechta D, et al. Lead debate goes on. Pediatrics 1994;94:408-10.

29 Kuehn R. Suppression of environmental science. Am J Law Med 2004;30:333-69.

30 McCrary SV, Anderson CB, Jakovljevic J, et al. A national survey of policies on disclosure of conflicts of interest in biometical research. N Eng J Med 2000;343:1621-6.

31 Michaels D, Wagner W. Disclosure in regulatory science. Science 2003;302:2073.

32 Moses $\mathrm{H}$, Martin J. Academic relationships with industry. JAMA $2001 ; 285: 933-5$

33 Resnik DB, Shamoo AE. Conflict of interest and the university. Account Res 2002;9:45-64.

34 Union of Concerned Scientists. Available at http://www.ucsusa.org/ global_environment/rsi (accessed 10 August 2004).

35 Union of Concerned Scientists. Scientific Integrity in Policymaking. Available at hitp:// www.ucsusa.org (accessed 18 October 2004)

36 Ashford NA, Castleman B, Frank AL, et al. The International Commission on Occupational Health $(\mathrm{ICOH})$ and its influence on international organizations. Int J Occup Environ Health 2002;8:156-62.

37 Union of Concerned Scientists. Available at http://www.ucsusa.org/news (accessed 18 October 2004).

38 Union of Concerned Scientists. Available at http://www.ucsusa.org/rsi (accessed 18 October 2004)

39 Robbins A. Science policy and politics: Will the recent past preface the future? Epidemiol 2005;16:406-9.

40 Wu R. Making an impact. Nature 2004;428:206-7.

41 Poo MM. Culture reflections. Nature 2004;428:204-5.

42 Campbell P. Message to China from the west. Nature 2004;428:203. 